\title{
Choque térmico na superação da dormência de diásporos de Tectona grandis $\mathrm{L}$. $\mathrm{f}$.
}

Thermal shock to overcome the dormancy of diaspores Tectona grandis L. f.

\author{
R. Q. S. Ferreira'; M. O. Camargo ${ }^{2}$; M. R. Souza Junior ${ }^{3}$; P. B. Souza ${ }^{4}$ L. \\ M. Oliveira ${ }^{5}$ \\ ${ }_{1}$ Programa de Pós-Graduação em Ciências Florestais e Ambientais, Universidade Federal do Tocantins, \\ 77402-970, Gurupi-Tocantins, Brasil \\ romulo_florest@uft.edu.br
}

(Recebido em 30 de abril de 2015; aceito em 16 de fevereiro de 2016)

\begin{abstract}
O objetivo deste trabalho foi testar tratamentos pré-germinativos para superar dormência de diásporos de Tectona grandis L. f.O experimento foi conduzido no Laboratório de Sementes e no viveiro da UFT Campus de Gurupi. A coleta dos diásporos foi realizada emseis árvores matrizespresentes no sistema agroflorestal. Os tratamentos testados foram: (T1) diásporos intactos; (T2) aquecimento dos diásporos em estufa a $80^{\circ} \mathrm{C}$ por $12 \mathrm{~h}$, sem imersão em água; (T3) aquecimento dos diásporos em estufa a $80{ }^{\circ} \mathrm{C}$ por 12 h, seguido de imersão em água por $6 \mathrm{~h}$; (T4) aquecimento dos diásporos em estufa a $80{ }^{\circ} \mathrm{C}$ por $12 \mathrm{~h}$, seguido de imersão em água por $8 \mathrm{~h}$; (T5) aquecimento dos diásporos em estufa a $80{ }^{\circ} \mathrm{C}$ por $12 \mathrm{~h}$, seguido de imersão em água por 10 h; (T6) embebição por 16 h dos diásporos à noite e aquecimento ao sol por 8h durante o dia, seguido de embebição no final por $24 \mathrm{~h}$; (T7) embebição por $16 \mathrm{~h}$ dos diásporosà noite e aquecimento ao sol por $8 \mathrm{~h}$, por três dias, e embebição no final por $24 \mathrm{~h}$. Foi avaliada a emergência de plântulas, índice de velocidade de emergência, comprimento e biomassa. As médias foram submetidas à análise de variância e comparadas pelo teste de Tukey a 5\% de probabilidade.Conclui-se que o tratamento (T2) proporcionou os melhores resultados de porcentagem e índice de velocidade de emergência, mas ainda proporcionou baixos valores, necessitando novos estudos com essa espécie.

Palavras - chave: dormência, diásporos, emergência
\end{abstract}

The objective of this study was to testpre-germinationtreatments to overcome Tectona grandis L. f. diaspores dormancy. The experiment was conducted at the UFT Laboratory of Seed and seedling nursery - Campus of Gurupi. Six parent trees were utilized as seed providers, all of them located in the agroforestry system. The treatments were: (T1) intact seeds; (T2) seed heating in an oven at $80{ }^{\circ} \mathrm{C}$ for 12 $\mathrm{h}$ without immersion in water; (T3) seed heating in an oven at $80^{\circ} \mathrm{C}$ for $12 \mathrm{~h}$, followed by immersion in water for $6 \mathrm{~h}$; (T4) seed heating in an oven at $80^{\circ} \mathrm{C}$ for $12 \mathrm{~h}$, followed by immersion in water for 8 hours; (S5) seed heating in an oven at $80{ }^{\circ} \mathrm{C}$ for $12 \mathrm{~h}$, followed by immersion in water for $10 \mathrm{~h}$; (T6) seed soaking for $16 \mathrm{~h}$ at night and warming in the sun for 8 hours during the day, followed by immersion in the end for $24 \mathrm{~h}$; (T7) seed soaking for $16 \mathrm{~h}$ at night and warming in the sun for 8 hours, for three days, and at the end, soaking for 24 hours. Seedling emergence, emergency speed index, length and mass were biomass. The mean results were submitted to analysis of variance and compared by Tukey at 5\% probability.We conclude that treatment (T2) provided the best results percentage and emergency speed index, but still gave low values, requiring further studies with this species.

Key words: dormency, diaspores, emergency

\section{INTRODUÇÃO}

Dentre os mais variados sistemas de produção o setor florestal sempre teve recursos para a confecção de objetos e materiais de consumo, importantes para o ser humano, como: material para construção civil, indústria moveleira, indústria naval, siderurgia, papel e celulose e produtos não madeireiros, tais como óleos essenciais, frutos, taninos dentre outros [1].

O setor florestal sempre busca novas alternativas de renda como a domesticação de novas espécies que tendem a ter alto valor econômico agregado. Mesmo tendo como característica ciclos de cultivo longos, tornando esta atividade um investimento a longo prazo, podem gerar grandes lucros aos investidores, e para isto necessita-se de espécies que apresentem madeira de qualidade. Neste contexto os produtores de madeiras vêm pesquisando e observando diversas 
espécies de alto valor comercial para desenvolver seus plantios,Tectona grandis L. f é uma das espécies que vem se destacando em diversas regiões do mundo.

Tectona grandisL. f., popularmente conhecida por teca, é uma espécie florestal originária das florestas tropicais de monção do sudeste da Ásia (Índia, Myanmar, Tailândia e Laos) que foi introduzida na região norte do Brasil em 1994 para cumprir a reposição florestal obrigatória em atendimento à legislação ambiental [2].

É uma das espécies mais utilizadas na composição de projetos de reflorestamento devido ao baixo rendimento que é observado pelos produtores quando se utiliza espécies nativas. Essa espécie se comporta de forma rústica em plantios puros, consorciados e em sistemas produtivos integrados com a presença de animais de médio e pequeno porte. Tolera vários climas, porém se desenvolve melhor em condições tropicais moderadamente úmidas e quentes, apresentando um maior rendimento e incremento volumétrico em regiões onde a precipitação anual fica entre $1250 \mathrm{~mm}$ e $3750 \mathrm{~mm}$ ano, temperatura mínima de $13{ }^{\circ} \mathrm{C}$ e máxima de $43{ }^{\circ} \mathrm{C}$, e uma estação biologicamente seca de três meses[3].

Os plantios dessa espécie estão concentrados nas regiões Norte e Centro - Oeste do Brasil, com destaque para os Estados de Roraima, Pará e Mato Grosso, e tem como finalidade a produção de madeira em torajá que traz maiores retornos econômicos.Devido as consideráveis propriedades tecnológicas e o ciclo de cultivo longo a mesma é caracterizada como espécie de uso nobre, sendo atualmente responsável por $0,4 \%$ da produção total de madeira em tora do Brasil, e seus plantios ocupam uma área de 67,329 ha em todo o território nacional [4].

Uma das principais limitações para a produção de mudas de Tectona grandis L. f. é a sua germinação lenta e irregular devido à dormência mecânica imposta pelas partes do fruto, pois as sementes estão inseridas dentro de frutos com endocarpo e mesocarpo com alta resistência à entrada de água. Devido a este fator apresenta germinação desuniforme com período variando de 10 a 90 dias, e baixas porcentagens de germinação são verificadas em campo com valores variando de 25 a $35 \%$. Sendo assim, percebe-se a necessidade de pesquisas relacionadas à produção de mudas, visando maior eficiência e economia na produção das mudas propiciando atender de forma adequada o mercado crescente e promissor [5].

A dormência é um fenômeno intrínseco da semente, funcionando como um mecanismo natural de resistência a fatores adversos do ambiente, podendo manifestar-se de três formas: dormência imposta pelo tegumento, dormência embrionária e dormência devido ao desequilíbrio entre as substâncias promotoras e inibidoras de germinação [6]. Já o processo germinativo compreende uma sequência de eventos fisiológicos, influenciado por fatores internos e externos, podendo estes atuar por si ou em interação. Os fatores internos são os reguladores e substâncias inibidoras não hormonais, enquanto que os externos são: umidade, temperatura, luz e oxigênio, tais fatores limitam a germinação das sementes, especialmente para os viveiristas que precisam produzir mudas em larga escala e com tamanho uniforme [7].

Resultados de pesquisas têm apontado que altas temperaturas, escarificação dos frutos, imersão em ácido sulfúrico, mantê-las por 24 horas sob água corrente ou imersão em água seguido de secagem natural são fatores decisivos para a superação de dormência dos diásporos de Tectona grandis L. f. [8, 9,10, 11, 12]. No entanto, os atuais procedimentos de superação de dormência dos diásporos da Tectona grandisL.f. se caracterizam pelo baixo rendimento operacional e menor praticidade, encontrando-se, atualmente, grande dificuldade quanto à metodologia mais adequada para a superação da dormência das unidades de dispersão dessa espécie [13].

Dessa forma, o presente trabalho teve como objetivo testar tratamentos pré-germinativos para superar a dormência de diásporos de Tectona grandis L. f. a fim de verificar a viabilidade dos mesmos e identificar o mais efetivo na promoção da germinação tendo em vista a produção de mudas uniformes e de qualidade.

\section{MATERIAL E MÉTODOS}

O experimento foi conduzido no Laboratório de Sementes e no viveiro de mudas da Universidade Federal do Tocantins - Campus de Gurupi. A coleta dos diásporos foi 
realizadamanualmente com auxílio de podão no mês de agosto de 2014 em seis árvores matrizes de Tectona grandis L. f. (Teca) presentes no sistema agroflorestal da Universidade Federal do Tocantins - Campus Gurupi, sob as respectivas coordenadas geográficas UTM 0712591 e 8701124. Posteriormente os diásporos foram acondicionados em sacos de papel e levados para o Laboratório de Análise de Sementes, onde foram beneficiados e submetidos a tratamentos prégerminativos para a superação da dormência (Tabela 1).

Tabela 1. Descrição dos tratamentos pré-germinativos aplicados nos diásporos de Tectona grandis L. $f$

\section{Descrição dos tratamentos}

T1 Diásporos intactos (testemunha).

T2 Aquecimento dos diásporos em estufa a $80^{\circ} \mathrm{C}$ por $12 \mathrm{~h}$, sem imersão em água.

T3 Aquecimento dos diásporos em estufa a $80^{\circ} \mathrm{C}$ por $12 \mathrm{~h}$, seguido de imersão em água por $6 \mathrm{~h}$.

T4 Aquecimento dos diásporos em estufa a $80^{\circ} \mathrm{C}$ por $12 \mathrm{~h}$, seguido de imersão em água por $8 \mathrm{~h}$.

T5 Aquecimento dos diásporos em estufa a $80^{\circ} \mathrm{C}$ por $12 \mathrm{~h}$, seguido de imersão em água por 10 h.

T6 Embebição por $16 \mathrm{~h}$ dos diásporos durante a noite e aquecimento ao sol por $8 \mathrm{~h}$ durante o dia, por um dia, seguido de embebição no final por $24 \mathrm{~h}$.

T7 Embebição por $16 \mathrm{~h}$ dos diásporos durante a noite e aquecimento ao sol por $8 \mathrm{~h}$ durante $\mathrm{o}$ dia, por três dias, seguido de embebição no final por $24 \mathrm{~h}$.

Após a realização dos tratamentos pré-germinativos os diásporos foram levados para o viveiro de mudas do Campus de Gurupi-UFT para a instalação do experimento. A semeadura foi realizada a uma profundidade de $2 \mathrm{~cm}$ em bandejas plásticas, perfuradas no fundo, contendo o substrato areia, previamente peneirando, lavado e esterilizado em autoclave a $120^{\circ} \mathrm{C}$ por uma hora, para manter o substrato úmido foram realizadas regas diárias. Para a semeadura foram utilizados 100 diásporos por tratamento, sendo subdividido em quatro repetições de 25 diásporos cada.

Para avaliar a qualidade fisiológica das sementes utilizaram-se os seguintes testes: emergência de plântulas, índice de velocidade de emergência (IVE), comprimento e biomassa seca de plântulas como descritos a seguir:

Emergência de plântulas - o critério adotado para efetuar a contagem de emergência de plântulasfoi quando os cotilédones apresentavam-se acima do substrato até os 63 dias quando houve a estabilização, sendo osresultadosexpressos em porcentagem. $O$ índice de velocidade de emergência (IVE) foi realizado juntamente com o teste de emergência, onde foram feitas contagens diárias tomando como critério os cotilédones que se apresentavam acima do substrato.

O índice de velocidade de emergência (IVE) foi realizado juntamente com o teste de emergência, onde foram feitas contagens diárias tomando como critério os cotilédones que se apresentavam acima do substrato, sendo os resultados calculados pela fórmula proposta por [14].IVE $=(\mathrm{G} 1 / \mathrm{N} 1)+(\mathrm{G} 2 / \mathrm{N} 2)+\ldots+(\mathrm{Gn} / \mathrm{Nn})$; em que G1, G2 ... Gn representam os números de plântulas emergidas na primeira, segunda, até a última contagem; e N1, N2... N os números de semanas desde a primeira, a segunda, até a última contagem.

Finalizado o teste de emergência, as plântulas foram retiradas das bandejas, sendoo material separado por repetição de acordo com cada tratamento,em seguida foram levadas para o laboratório de sementes para determinação do comprimento total com auxílio de régua milimétrica [15].

Biomassa seca das plântulas - após a medição das plântulas de cada tratamento as mesmas foram colocadas em sacos de papel para posterior secagem em estufa com circulação forçada de ar regulada, a $65^{\circ} \mathrm{C}$ onde permaneceram até atingir peso constante. Após este período, as amostras foram resfriadas e pesadas em balança de precisão de $0,001 \mathrm{~g}$ [15]. 
Para as avaliações de todos os testes de vigor foi considerada uma plântula por unidade de dispersão devido a cada fruto conter de uma a quatro sementes viáveis, portanto para cada diásporo foi considerado apenas um indivíduo.

O delineamento experimental foi inteiramente casualizado perfazendo sete tratamentos compostos de quatro repetições cada. Os dados expressos em percentagens foram previamente transformados em arscen (raiz x/100). As médias foram submetidas à análise de variância $\mathrm{e}$ posteriormente comparadas pelo teste de Tukey a $5 \%$ de probabilidade.

\section{RESULTADOS E DISCUSSÃO}

Conforme os dados apresentados na Tabela 2 se podenotar que o tratamento pré-germinativo (T2) baseado no aquecimento em estufa a $80^{\circ} \mathrm{C}$ por 12 horas sem imersão em água proporcionou a maior porcentagem de emergência de plântulas (35\%) quando comparado aos demais tratamentos, proporcionando também o maior índice de velocidade de emergência $(0,281)$. Por outro lado, os tratamentos pré-germinativos (T3, T4 e T5) em que os diásporos foram aquecidos à $80^{\circ} \mathrm{C}$ por 12 horas e seguidos por embebição em água com alternância de tempo (6, 8, e 10 horas, respectivamente) proporcionaram redução na expressão do vigor.

Mas esses valores ainda são considerados baixos quando a finalidade é a produção de mudas em larga escala, o que demanda o uso de maior quantidade de fruto-semente gerando, assim, um custo adicional para o produtor, por isso é esperado que o tratamento pré-germinativo proporcione maior porcentagem e velocidade de emergência das plântulas com vistas à obtenção de mudas uniformes.

Tabela 2. Porcentagem de emergência (\%), índice de velocidade de emergência (IVE), comprimento e biomassa seca de plântulas de Tectona grandis L. $f$.

\begin{tabular}{ccccc}
\hline Tratamentos & Emergência (\%) & IVE & Comprimento (cm) & Biomassa seca (g) \\
\hline T 1 & $7 \mathrm{~d}$ & $0,061 \mathrm{~b}$ & $14,31 \mathrm{a}$ & $0,196 \mathrm{a}$ \\
T 2 & $35 \mathrm{a}$ & $0,281 \mathrm{a}$ & $11,68 \mathrm{ab}$ & $0,162 \mathrm{ab}$ \\
T 3 & $27 \mathrm{ab}$ & $0,183 \mathrm{ab}$ & $9,48 \mathrm{ab}$ & $0,095 \mathrm{ab}$ \\
T 4 & $25 \mathrm{ab}$ & $0,213 \mathrm{ab}$ & $10,69 \mathrm{ab}$ & $0,111 \mathrm{ab}$ \\
T 5 & $22 \mathrm{abc}$ & $0,182 \mathrm{ab}$ & $12,04 \mathrm{ab}$ & $0,162 \mathrm{ab}$ \\
T 6 & $12 \mathrm{bcd}$ & $0,115 \mathrm{~b}$ & $11,94 \mathrm{ab}$ & $0,125 \mathrm{ab}$ \\
T 7 & $9 \mathrm{~cd}$ & $0,056 \mathrm{~b}$ & $8,25 \mathrm{~b}$ & $0,049 \mathrm{~b}$ \\
\hline CV (\%) & 19,34 & 44,05 & 19,86 & 44,84 \\
\hline
\end{tabular}

Comparando os resultados deste estudo com o realizado por [11] observa-se que há controvérsias, pois ao utilizar o mesmo tratamento pré-germinativo (aquecimento do diásporo em estufa a $80{ }^{\circ} \mathrm{C}$ por 12 horas, seguido de imersão em água corrente por seis horas) os referidos autores constataram a melhor expressão do índice de velocidade de germinação $(1,58)$ e porcentagem de germinação (78\%), enquanto nessa pesquisa a porcentagem de plântulas emersas após a germinação foi apenas $27 \%$.

Por outro lado, [16] ao avaliar o potencial de germinação de teca pós - colheita e aos 120 dias após o armazenamento constatouque a viabilidade dos diásporos, não tratados, reduziu de 58 para $28 \%$ com o período de estocagem, cujos resultados também diferem do presente estudo quando se trata da capacidade de germinação após a colheita. Evidenciando com isso a divergência de resultados entres os autores citados. 
A provável explicação para a variabilidade de resultados entre os diferentes autores se justifica pela desuniformidade quanto ao tamanho dos frutos, quantidade de sementes por fruto e, ainda, a viabilidade dos mesmos. Podendo ser confirmado pelo estudo realizado em Mato grosso por [23] com três lotes de Tectona grandis L.f onde se constatou variabilidade quanto às características físicas dos frutos, exemplificados pelo peso de mil $0,681 \pm 0,032 \mathrm{~kg}$; número de frutos por quilograma 1.471 \pm 72 ; e dos frutos que não apresentaram emergência em que $69,6 \%$ não continha qualquer semente enquanto as demais apresentaram uma, duas ou três sementes por fruto. Tais resultados indicam que a baixa emergência verificada no presente estudo esteja relacionada tanto com a presença de dormência quanto a possibilidade de ocorrência de diásporos sem sementes e,ainda, sementes inviáveis.

Nos ensaios realizados por [13] foi verificado que o calor de $80^{\circ} \mathrm{C}$, temperatura obtida em um solarizador que simulava a estufa, proporcionou a germinação de $66 \%$ dos diásporos, cujo tratamento é similar ao testado neste estudo, porém o resultado foi inferior (35\%), novamente mostrando a discordância de resultados entre os autores.

Resultados de pesquisa de [17] têm mostrado que o uso de estufa a $80^{\circ} \mathrm{C}$ tem proporcionado resultado satisfatório, obtendo-se porcentagem de germinação de $78 \%$, pois os autores argumentam que a alternância de temperatura tem efeito benéfico na resposta fisiológica das sementes que estão inseridas dentro do fruto, sendo essa técnica importante para o enfraquecimento do mesocarpo e endocarpo, cujas estruturas são barreiras mecânicas que limitam a germinação. No presente trabalho foi utilizada a mesma técnica, no entanto, o resultado foi inferior. Provavelmente fatores como a qualidade dos frutos coletados possa ter interferido nos valores verificados, uma vez que na amostra de diásporos podem apresentar unidades com diferentes épocas de maturação fisiológica, no entanto não foi encontrado relatos na literatura quanto à influência da maturação sobre a germinação de frutos-sementes de teca.

Ainda segundo [11] o fator limitante para a produção de mudas de teca é a presença de endocarpo e mesocarpo duro de alta resistência revestindo a semente, por isso, a germinação se dá naturalmente de forma lenta e irregular, o que caracteriza um tipo de dormência. Portanto, o melhor procedimento para superar a dormência é aquele que promova a redução da resistência mecânica sem afetar a viabilidade das sementes [18]. E adicionalmente, segundo [23] outro fator que contribui para a baixa porcentagem de emergência em sementes dessa espécie é a ausência de sementes no fruto.

Os tratamentos T6 e T7 consistiram de embebição, aquecimento e nova embebição com a finalidade de causar o choque térmico para promover aceleração da germinação, mas os resultados mostram que não surtiram efeito já que os valores foram estatisticamente semelhantes aos diásporos não tratados (T1) (Tabela 2). Apesar de não ter proporcionado o resultado esperado, a embebição em água e posterior secagem ao ar livre constituem a opção mais prática e segura para pequenos produtores florestais, além de ser um método simples, de baixo custo e eficaz para promover uma germinação rápida e uniforme [19]. O Tratamento 7 (embebição por $16 \mathrm{~h}$ dos diásporos durante a noite e aquecimento ao sol por $8 \mathrm{~h}$ durante o dia, por três dias, seguido de embebição no final por 24h), técnica recomendada por [20] também foi testada neste estudo mas os resultados mostram que não houve efeito devido aos baixos valores obtidos para a velocidade e porcentagem de emergência de plântulas. Ainda segundo o autor, quando o frutosemente é de qualidade essa técnica possibilita o início da germinação em poucos dias, mas algumas unidades podem demorar meses para germinar. Isso sugere que, provavelmente, os diásporos utilizados tenham baixa viabilidade, apesar de não ter sido feito teste que pudesse confirmar essa suposição.

Com relação às variáveis comprimento e biomassa seca de plântulas observou-se que o melhor e pior resultado foram observados em T1 e T7 (Tabela 2), respectivamente, ressaltando que em T1 os diásporos não foram submetidos a nenhum tratamento, enquanto para os demais tratamentos (T2, T3, T4, T5 e T6) não houve diferença estatística. Nota-se que as plântulas oriundas do tratamento $\mathrm{T} 1$ apresentaram em média o maior o comprimento e consequentemente a maior quantidade de biomassa acumulada, o qual pode ser explicado provavelmente pela maior quantidade de material de reserva presente nas sementes. No entanto, o tratamento T2 foi o que proporcionou maior porcentagem e índice de velocidade de emergência, assim, supõem-se 
que embora tenha germinado mais sementes, estas originaram em média plântulas menores e com menos biomassa.

Os testes de vigor comprimento e massa seca de plântulas são comumente utilizados na avaliação das plântulas, sendo assim, sementes mais vigorosas possuem maior taxa de crescimento em função da maior capacidade de transformação e suprimento das reservas dos tecidos de armazenamento pelo eixo embrionário, enquanto a determinação da biomassa seca é outra forma de avaliar o crescimento das plântulas através da matéria seca acumulada nos tecidos [21, 22]. Tais resultados sugerem que a germinação natural possibilita $o$ desenvolvimento de plântulas mais vigorosas, mas em contrapartida o número de plântulas emersas é reduzido.

\section{CONCLUSÃO}

$\mathrm{O}$ tratamento que proporcionou os melhores resultados de porcentagem e índice de velocidade de emergência foi aquele baseado no aquecimento dos diásporos em estufa a $80{ }^{\circ} \mathrm{C}$ por $12 \mathrm{~h}$, sem imersão em água (T2), mas ainda proporcionou baixos valores, necessitando novos estudos com essa espécie.

Os testes de comprimento e biomassa seca de plântulas indicam que as plântulas mais vigorosas são obtidas sem o tratamento dosdiásporos.

\section{REFERÊNCIAS BIBLIOGRÁFICAS}

1. Macedo RLG, Venturin N, Gomes JE, Oliveira TK. Dinâmica de estabelecimento de Tectona grandis L. f. (Teca) introduzida em cafezal na região de Lavras - Minas Gerais. Revista Brasil Florestal. 2002; 73: $31-38$

2. Figueiredo EO, Oliveira AD, Scolforo JRS. Análise econômica de povoamentos não desbastados de Tectona grandis L. f. na microrregião do baixo rio Acre. Revista Cerne. 2005; 11(4): 342- 353.

3. Krishnapillay B. Silvicultura y ordenación de plantaciones de teca. Revista Unasylva. 2000; 51(201): 14-21.

4. ABRAF. Anuário estatístico da Abraf. Brasília: ABRAF. 2013. 148 p.

5. Kaosa - Ard A. Teak (Tectona grandis L. f.) nursery techniques with special reference to Thailand. Humiebaeck Denmark - Danida Forest Seed Centre; 1986.42 p.

6.Bewley JD, Black M. Seeds: physiology of development and germination. New York: Plenum; 1994. $445 \mathrm{p}$.

7. Rebelo AM. Estudo de aspectos morfológicos e de crescimento quantitativo de Tectona grandis (L. f.) no estado de Rondônia. Porto Velho - RO: FundaçãoUniversidade Federal de Rondônia, 2003. 56p.

8. Figueiredo EO. Teca (Tectona grandisL.f.): produção de mudas tipo toco. Rio Branco - AC: Embrapa Acre, 2005. $24 \mathrm{p}$.

9. Dias RM, Caproni AL, Wadt PGS, Silva LM, Tavella LB, Oliveira JP. Quebra de dormência em diásporos de teca (Tectona grandis L. f.). Revista Acta Amazônica. 2009; 39(3): 549 - 554.

10. Brasil. Ministério da Agricultura, Pecuária e Abastecimento. Secretaria de Defesa Agropecuária. Regras para Análise de Sementes. MAPA/ACS, 2009. 395p.

11. Vieira AH, Rocha RB, Rebelo A M. Avaliação de métodos para a superação de dormência de diásporos de teca (Tectona grandis L.f.). Revista Floresta. 2009; 39(2): 273-278.

12. Castilho RMM, Farsoni PH, Rossi R. Germinação e desenvolvimento de mudas de Tectona grandis. Revista Tecnologia \&Ciência Agropecuária. 2014; 8(4): 23-28.

13. Rocha R B, Vieira AH, Spinelli VM, Vieira JR. Caracterização de fatores que afetam a germinação de teca (Tectona grandis): temperatura e escarificação.Revista Árvore. 2011; 35(2): 205-212.

14. Maguire JD. Speed of germination-aid and in selection and evaluation for emergence and vigor. Magazine Crop Science. 1962; 2(1): 176-177.

15. Oliveira LM, Bruno RLA, Alves EU, Sousa DMM, Andrade AP. Tratamentos pré-germinativos em sementes de Samanea tubulosa Bentham - (Leguminoseae- Mimosoideae). Revista Árvore. 2012; 36(3): 433-440.

16. Coimbra EC, Vazquez GH, Nogueira TO. Superação da dormência e o uso de fungicida em diásporos de teca. Revista Brasileira de Engenharia Agrícola e Ambiental. 2014; 18(12):1281-1286.

17. Pasa MC, Binsfeld TJBN. Germinação de Tectona grandis L. f. e a etnobotânica no distrito de Água da Prata. Brasnorte, Mato Grosso. Revista Flovet. 2012; 4: 22-32. 
18. Piña-Rodrigues FCM, Jesus RM. Comportamento das sementes de cedro-rosa (CedrelaangustifoliaS. et. Moc) durante o armazenamento. Revista Brasileira de Sementes. 1992; 14(1): 31-36.

19. Cáceres F. Manual do reflorestamento da teca. Cáceres Florestal S/A. Cáceres: Mato Grosso. 1997. 31 p.

20. Bewley JD, Black M. Seeds: physiology of development and germination. New York: Plenum; 1994. $445 \mathrm{p}$.

21. Dan EL, Mello VDC, Wetzel CT, Popiginis F, Souza EP. Transferência de matéria seca como método de avaliação do vigor de sementes de soja. Revista Brasileira de Sementes. 1987; 9(3): 45-55.

22. NakagawaJ. Testes de vigor baseado no desempenho das plântulas. In: Krzyzanowski FC, Vieira RD, França Neto JB. Vigor de sementes: conceitos e testes. Cap. 2. Londrina: ABRATES, 1999. 24 p.

23. Caldeira SF, Caldeira SAF, Mendonça EAF, Diniz NN. Caracterização e avaliação da qualidade dos frutos de (Tectona grandis L. f) produzidos no Mato Grosso. Revista Brasileira de Sementes. 2000; 22(1): 216-224. 